\title{
A grande forma de familia- \\ Em defesa de uma família inventada
}

\author{
Great family way - In defense of an invented family
}

Danilo Sales de Queiroz Silva ${ }^{1}$

\begin{abstract}
RESUMO: O artigo explora o desenvolvimento do conceito de família no discurso ficcional de Valter Hugo Mãe. Recorrendo à leitura do romance O filho de mil homens (2011), propõe-se a discussão e alargamento desse conceito. Considerando família como estrutura capaz de amparo e responsabilização pelos membros, escolhidos livre e afetivamente, o modelo desse grupo se amplia consideravelmente no texto do escritor português. A leitura analítica do romance é acompanhada pela crítica sociocultural, a fim de apontar as transformações sofridas por essa forma de organização social e desestabilizar políticas que restringem o espartilho familiar. Segue-se a ideia de que as "famílias em desordem", mutiladas pelo despedaçamento da ordem unívoca que as sustentou (ROUDINESCO, 2003), reconfiguram-se novas dinâmicas. A família assume a característica de ser "frágil, porosa e expansiva" (BUTLER, 2001, p. 41). O parentesco emerge como paradigma de uma 'afiliação consensuada' ou uma 'organização social de uma necessidade' - em outros termos, nasce a possibilidade de 'invenção' de uma família. Porém, essas formas de 'família' se articulam fragilmente com o Estado e sociedade. A narrativa de Mãe incide no turbilhão desse rearranjo e desarranjo familiares.
\end{abstract}

PALAVRAS-CHAVES: Valter Hugo Mãe; Literatura comparada; Família; Crítica social; Romance.

ABSTRACT: The article explores the development of the concept of family in the fictional discourse of Valter Hugo Mãe. Resorting to the reading of the novel The son of a thousand men (2011), it is proposed the discussion and extension of this concept. Considering family as a structure able to protect and hold members freely and affectionately chosen, the model of this group expands considerably in the text of the Portuguese writer. The analytic reading of the novel is accompanied by sociocultural critique in order to point out the transformations undergone by this form of social organization and to destabilize policies that restrict the family corset. It follows that "families in disorder", mutilated by the shredding of the univocal order that sustained them (ROUDINESCO, 2003), reconfigures new dynamics. The family assumes the characteristic of being "fragile, porous and expansive" (Butler 2001: 41). Kinship emerges as a paradigm of a 'consensual affiliation' or a 'social organization of a need' - in other words, the possibility of 'invention' of a family arises. However, these forms of 'family' are frailly articulated with the state and society. The narrative of Mother focuses on the whirlwind of this family rearrangement and disarray.

KEY-WORDS: Valter Hugo Mãe; Comparative literature; Family; Social criticism; Novel.

\footnotetext{
${ }^{1}$ Doutorando do Programa em Literatura e Cultura pela UFBA, Universidade Federal da Bahia, é Mestre e Graduado em Letras pela UFBA. Atua nos seguintes temas: família contemporânea, literatura comparada, literatura portuguesa, literatura brasileira e sociedade. E-mail: danilosalesqueiroz@hotmail.com.
} 


\section{LAÇOS CRIADOS}

Acreditou que o afeto verdadeiro era o único desengano, a grande forma de encontro e de pertença. A grande forma de familia.

Sentia uma urgência grave sem saber ainda o que fazer.

Abriu a sua porta e arriscou sorrir. Imaginou, assim como num sonho, que uma criança abandonada poderia estar passando e quisesse entrar. Sonhou que um filho mais demorado poderia enfim descobrir o caminho para sua casa e ocupar o seu lugar no sofá onde o boneco de pano permanecia com um sorriso tão alegre, mas indiferente, um sorriso feito de botões vermelhos (MÃE, 2011, p. 11-12; grifo meu).

Crisóstomo, protagonista de O filho de mil homens, é um pescador que chega aos quarenta anos e tem vontade de ser pai. Guiado por um desejo irredutível, seus dias passam a ser ocupados pela esperança de encontrar uma criança perdida, com a qual poderá formar família. No trecho citado, seu desejo urgente aparece como motivador de uma abertura para o encontro: a partir de então, mostrar-se-á disposto a constituir uma família vindoura, por afinidades e uniões fortuitas. A grande forma de família seria o afeto, "grande forma de encontro e de pertença". Essa forma de família, entretanto, requer outra construção dos seus membros, pois não repousa sobre vínculos de sangue e geração de casamento. $O$ estudo aqui proposto tem como objetivo primeiro pensar as conseqüências e desdobramentos dessa família inventada.

A constituição e união familiar, em foco nesse romance, parecem uma questão central às narrativas de Valter Hugo. Problematizada nos romances anteriores do escritor português, a família tem um papel especialmente importante no cuidado e segurança de seus membros. O romance $A$ máquina de fazer espanhóis narra o final da vida de António Jorge da Silva, um homem idoso que chega ao asilo depois de perder orientação e laços com o mundo, devido à morte de sua companheira. Isolado, ele irá reorganizar sua vida privada no contato com os demais idosos. Publicado em 2010, o romance fecha a teratologia das letras minúsculas que consolidou o primeiro momento da produção narrativa do autor, que buscava sondar as diversas idades do homem - $O$ nosso reino (de 2004) relativo à infância, $O$ remorso de Baltaz̧ar serapião (de 2006) relativo à juventude e $O$ apocalipse dos trabalhadores (de 2008) relativo à maturidade.

Algo de terrível se insinuava no corpo social a que aludem as narrativas, assim como esse traço negativo se imiscuía nas relações íntimas dos personagens. Guardadas as diversas diferenças entre os romances, eles apontavam para problemas na formação dos laços entre os personagens.

O menino que quer se tornar santo, Benjamin, protagonista de $O$ nosso reino, deve encarar a crítica social e enfrentar a solidão, pois a família entra em declínio (nos idos do 
Estado Novo), o pai começa a beber e espancar a mãe, seus irmãos morrem, e o cenário final é trágico e desolado para a criança.

O romance entre Baltazar e Ermesinda, núcleo protagonista da trama de $O$ remorso de Baltaz̧ar Serapião, é marcado pela violência e mutilação, que segue num crescente durante a narrativa (que se passa no reinado medieval de D. Dinis), marcando a condição dos Sarga (nome da vaca e epíteto pelo qual são chamados os Serapião, marcados como rudes e por uma forte animalização).

A mulher-a-dias Maria das Graças, protagonista de $O$ apocalipse dos trabalhadores, passa por extremos e a desumanização de Portugal (e do mundo ocidental) contemporâneo aparece com grande força na trama erótica que ocupa o início do livro: a relação desigual de empregada doméstica (maria das graças) com o erudito (senhor ferreira), marcada pela relação de trabalho e submissão e culminando num final trágico para os amantes. Em todos os casos, a formação de laços entre os personagens é problemática.

Esse investimento na figura familiar pelo romancista chama nossa atenção. Diversos discursos (da religião, dos "especialistas") dominam o pensamento sobre a família, muitas vezes atrelando decadência familiar à crise ética e moral dos nossos tempos ${ }^{2}$. Embora, por vezes, a destruição da família seja propagada em discursos apocalípticos como uma verdade dos nossos tempos, sua sobrevida não dá mostras de estar no final. Pelo contrário, a família demonstra ser ainda um grupo modelar, cuja transformação não abalou seus alicerces. Procuramos sondar, portanto, qual forma de família está ameaçada e, diante de sua sobrevida, repensar qual o papel familiar galvanizado pelo escritor no romance estudado.

Discutindo as transformações pelas quais passou a família, Elisabeth Roudinesco afirma que um dos mais importantes golpes recebidos pela ordem simbólica não foi a tentativa de sua supressão, mas sim a iniciativa, de grupos anteriormente excluídos dessa ordem, de se integrarem a ela. Mais precisamente, a partir do momento em que casais gays e lésbicos decidiram adotar filhos e se adequar à estrutura que parecia exclui-los, reclamando direitos iguais na formação de uma família, os discursos exaltados sobre a destruição do grupo familiar ganharam mais força. Portanto, longe da ilusão de sua degradação, entendemos a variabilidade atual da família como o desdobramento de sua potencialidade de captação afetiva. Ao falar sobre o futuro da família diante de tantas

\footnotetext{
2 Sobre isso, diz-nos Maria Rita Kehl: “A dissolução do espaço público em vários países do Ocidente - que no Brasil ganha contornos dramáticos - e a passagem de uma ética da produção para uma ética do consumo, entre outros fatores, são os grandes responsáveis pela desmoralização da transmissão familiar dos valores, e não o contrário." Disponível em: http://www.fronteiras.com/artigos/maria-rita-kehl-em-defesa-da-familiatentacular.
} 
transformações e da perda da hegemonia da família tradicional, a psicanalista conclui que "a família contemporânea, horizontal e em redes, vem se comportando bem e garantindo corretamente a reprodução das gerações" (ROUDINESCO, 2003, 197).

A deformação familiar não se dá, portanto, como uma dissolução do grupo, mas como extinção do modelo de família nuclear burguesa. Essa família, ameaçada por um molde mais expansivo e menos rígido, dá mostras de abalo. A organização social a que todos estamos submetidos, contudo, permanece fundamentando indivíduos e como parte importante de toda comunidade. A família aponta um núcleo de resistência, uma referência ainda desejada diante do "grande cemitério de referências patriárquicas desafetadas que são o exército, a Igreja, a nação, a pátria, o partido” (ROUDINESCO, 2003, 199). Nesse sentido, o conceito de família ganha contornos políticos e mobiliza discursos refratários à sua transformação.

A garantia dos nomes de Pai e Mãe se atrelam de tal forma à ordem social como um todo, que os deslocamentos propostos pela expansão da sociabilidade familiar é visto como um absurdo apocalipse do convívio funcional ${ }^{3}$, resultado de um golpe na ordem simbólica ${ }^{4}$. A luta política pela maior abrangência do conceito de família ainda é cerrada. Os temas da reprodução biológica e dos valores simbólicos se expandem no debate, porém, a lei que determinam não impede o processo adotivo, a fertilização in vitro ou a educação das crianças. Antes, os poderes desses discursos são ameaçados pela emergência de novas possibilidades de troca afetiva e conformações de ordens familiares diversas.

Acompanhamos o estudo de Judith Butler em O grito de Antígona. Revolvendo os comentários críticos sobre a personagem Antígona de Sófocles, Butler desenvolve diálogo com as apropriações que a personagem do drama teve pelos estudiosos, notadamente Hegel e Lacan. Na interpretação da filósofa americana, essa personagem tem uma posição

\footnotetext{
${ }^{3}$ Diante da iniciativa de construção do Estatuto da Diversidade Sexual, discursos desfavoráveis à proposta se pronunciavam contra o "fim da família". Em seu programa televisivo, Silas Malafaia, pastor de grande influência política no Brasil, alardeava o crime da "dissolução da família" que estava no Estatuto. Um dos trechos mais criticados por essa corrente ideológica tratava da substituição, nos documentos identificatórios, das denominações "pai" e "mãe" por "filiação" (Título VI, Art. 32). O colunista da Veja Reinaldo Azevedo, quando da notícia de comemoração do "Dia de quem cuida de mim" em escola paulistana, exalta-se contra a insubmissão à ordem simbólica: "Todo mundo sabe que boa parte das tragédias sociais e individuais tem origem em famílias desestruturadas". Disponível em: < http://veja.abril.com.br/blog/reinaldo/geral/escolasde-sp-acabam-com-o-dia-das-maes-e-institui-o-dia-dos-cuidadores-viva-o-fim-da-familia-prefeito-fernandohaddad $/>$.

4 Levamos em consideração a análise da psicanalista Elisabeth Roudinesco a respeito do desejo de normatividade que atinge casais homossexuais e vai marcando uma oposição cada vez mais acirrada na luta pela abrangência do conceito de família. Diz a autora: "Quando os gays e lésbicas da costa californiana quiseram, a partir de 1965-70, se tornar pais, inventaram uma cultura da família que não passava, sob muitos aspectos, da perpetuação do modelo que haviam contestado e que já se encontrava ele próprio em plena mutação. E foi exatamente porque essa cultura carregava consigo um grande desejo de normatividade que foi acolhida como a pior das feridas infligidas à ordem simbólica" (ROUDINESCO, 2003, p. 181).
} 
crucial para o pensamento da Lei e seus limites, colocando em destaque as leis não escritas que são condições prévias ao surgimento da própria Lei. No drama grego, a ordem instituída pelo poder de Creonte entra num ponto de tensão em que as leis não escritas também permanecem (o édito que deixa o cadáver insepulto é uma afronta aos deuses assim como ao amor fraterno) e tentam tomar posição na ordem instituída por meio da linguagem do poder. Numa inversão constante dos papéis socialmente delineados Antígona é comparada a um homem por sua atitude corajosa e exaltada, as relações de parentesco deslizam, já que ela é ao mesmo tempo irmã e filha de Édipo, sua estirpe a torna uma figura nobre comparada com a linhagem de Creonte, que está no trono -, o drama deixa em destaque a potência da linguagem e sua relação com a instituição da ordem. A relação entre linguagem, ordem, família e normalização aparece com grande força. Toda essa articulação ainda se relaciona ao ciclo mítico e à repetitividade que ele exige. Aí incide fortemente a crítica de Butler: não será justamente a afirmação dessa Lei como uma estrutura psíquica e simbólica, distinta da configuração social em movimento, que engendra seus limites e faz valer a sua perversão?

Assumindo a variabilidade do modelo familiar, o romance $O$ filho de mil homens apresenta-nos famílias que são (re)ordenadas segundo as possibilidades de integração entre seus membros. As relações familiares são deslocadas e outra imagem de parentesco aparece no discurso do autor. Dessa maneira, ele parece se livrar do enredo disjuntor anunciado pelo emaranhado da família nas representações mitopoéticas, que tem pontos de contato com a decadência familiar. Os romances da teratologia supracitada de Valter Hugo anunciavam o problema da formação de laços, amorosos e parentais; o ambiente social aparecia criticado nas narrativas (seja a época medieval ou, principalmente, o governo salazarista); havia uma preocupação central com o tema da família e da (de)formação dos laços humanos. Cabe, portanto, remontar a uma espécie de quadro dessa tradição literária para pensar na posição do autor e seu discurso sobre a família.

\section{UMA RESPOSTA À DECADÊNCIA FAMILIAR}

A decadência pode ser entendida como resultado da quebra da continuidade público/privado, procedimento que altera o modo de organização do poder na medida em que foi afetada a própria natureza das relações sociais. Influências individualistas e coletivistas se apresentam como desagregadoras do sistema patriarcal. Nesse sentido, é a família, como grande força permanente na formação nacional e influência conservadora e disseminadora dos valores patriarcais, a grande ameaçada (QUARESMA, 2007, p. 107). 
A família desestruturada oferecia uma interpretação da descontinuidade do laço social e da relação problemática entre público e privado por meio da tragédia que acometia seus membros. Esse grupo, estrutura cultural a qual somos todos submetidos por um tácito contrato, é uma condição sine qua non da sociedade em que vivemos. Nessas narrativas, parece haver um destaque para o problema de toda conformação social (obviamente condensando características da sociedade a que referem), que encontra na família sua expressão mais concentrada. As famílias representadas obedecem às estruturas conservadoras que impõem sua existência como pilar da sociedade. Como consequência, o desvio das novas gerações deve ser rechaçado, pois esse grupo fechado procede pela exclusão de outras formas de determinação de laços afetivos ou de vivências individuais. Como afirmado pelo estudioso supracitado, "influências individualistas e coletivistas se apresentam como desagregadoras do sistema patriarcal". O ideal tirânico de família - tal como formulado e conservado pela psicanálise tradicional, pela necessidade do Estado e pelas orientações da Igreja - formulado através da "triangulação edipianizante", impede o aparecimento de novas formas de sociabilidade e a saída do ciclo trágico a que foi reduzido o grupo familiar ${ }^{5}$.

As narrativas sobre as famílias malditas e destruídas são muito antigas. $\mathrm{Na}$ dissertação de mestrado, tentamos analisar de que forma essa disjunção familiar aparecia em romances de três autores de períodos e nações distintas, com o objetivo de formular uma visão sobre semelhanças entre os textos literários e os comentários que eles articulam sobre seus contextos. A ruptura familiar, que nesses romances (Os Buddenbrooks de Thomas Mann, Os Maias de Eça de Queirós e Cinzas do Norte de Milton Hatoum) tomava forma mais condensada na ruptura geracional (mais especialmente, na desunião entre pai e filho), na nossa leitura, encerraria uma crítica denunciando a dificuldade do surgimento e da manutenção de vínculos entre as gerações, deixando os personagens estéreis, ou seja, incapazes de se enraizar em seu tempo e de produzir frutos a partir daí, esterilizando também o mundo em volta.

A maldição na família é comum à mitologia grega. Urano guarda seus filhos em Gaia e é castrado por Cronos, o mais jovem deles. Esse, por sua vez, devora seus filhos para não sofrer a mesma sina, mas é banido por Zeus, seu filho - um dos capítulos de $O$

\footnotetext{
${ }^{5}$ Diz-nos Deleuze e Guattari sobre o papel da família assim considerada e suas implicações: "é a síntese de registro, primeiramente, que põe, sobre a sua superfície de inscrição nas condições de Édipo, um eu determinável ou diferenciável em relação a imagens parentais que servem de coordenadas (mãe, pai). Há aí uma triangulação que, em sua essência, implica uma proibição constituinte, e que condiciona a diferenciação das pessoas: proibição do incesto com a mãe e de tomar o lugar do pai. Mas, é graças a um estranho raciocínio que se conclui que, já que isso é proibido, isso mesmo é que era desejado" (DELEUZE; GUATTARI, 2010, p. 97). Essa crítica é, em grande parte, retomada pela leitura de Judith Butler.
} 
filho de mil homens faz referência a esse ato de devorar filhos. O mito dos Labdácidas também trata do tema. Os dramas que focalizam a sina da família costumam se acumular em torno do mesmo problema. Há uma tradição que percorre a representação literária. No caso da literatura portuguesa, a representação da disjunção familiar toma forma em $O s$ Maias de maneira particular. A crise que se instaura na família, cuja origem remete à educação de Carlos da Maia assim como ao incesto em que incorre, também parece remeter à noção de fatalidade, da mesma forma que indica um embate de valores e uma desconexão social. Essas representações parecem se contrapor à família que aparece no romance de Valter Hugo. De fato, sua narrativa remete à decadência familiar como uma resposta.

Dialogando com a tradição da maldição familiar, o escritor oferece uma inversão desse panorama trágico, baseado na assunção de um novo paradigma de valores que podem se sustentar em uma base comum e aliada ao passado. A visão do autor nesse romance não é negativa nem parece corrosiva em relação ao tempo presente, mas aponta para uma configuração possível e formata um discurso que evoque essa nova realidade. Sustentada pela linguagem, a ordem simbólica deve ser repetida e, nesse sentido, a narrativa compõe o tecer de uma rede imaginária que ganha força e substância. É uma participação na construção do universo imaginário do convívio em sentido amplo, e o afirma para criálo.

Compartilhando com a natureza seu desejo de ser pai, Crisóstomo encontra Camilo durante a jornada de trabalho e o leva para casa. O filho perdido - fruto da relação de uma anã, que se arrebenta durante o parto, com mais de dez homens - é desejado, encontrado e passa a pertencer ao homem que quer ser pai. Provocado por Camilo, Crisóstomo percebe que pode se expandir ainda mais e compartilha novamente com a natureza sua vontade de se duplicar e encontrar uma amante. Isaura aparece pela manhã sentada na areia em frente à casa do pescador, que decide se juntar a ela e tentar uma aproximação. $\mathrm{O}$ romance entre eles se desenvolve até a notícia de que Isaura é casada (por conveniência) com Antonino, o maricas. Esse personagem parece se opor à união estável do casal, mas é o convívio entre todos eles que fará a família. Discutidos os trâmites que possibilitariam a união como marido e mulher de Crisóstomo e Isaura, os três envolvem-se com harmonia A tentativa de formação desse núcleo familiar passa pelo afeto, alimentação e felicidade: o convívio e as trocas decorrentes dessa relação.

O romance, primeiro depois da teratologia, perde sinais de ambientação específica no tempo ou espaço: vila, praia e campo são imagens associadas aos personagens e suas 
ações; a duração também é incerta, mas presenciamos o crescimento de Camilo. A figura central, apesar do título, é Crisóstomo, um homem maduro - e, ao contrário dos protagonistas anteriores com idade semelhante, é um exemplo moral (seu nome ressoa Cristo). A união familiar é um aspecto central nesse livro, que convoca uma família inventada por afinidade, vontade e afeto. A educação sentimental, um dos temas mais caros à narrativa, passa à própria forma do romance, que assume tom mais lírico e empático em relação aos personagens. Imagens fantásticas surgem mais frequentemente. Enfim, esse romance parece mais determinar novos caminhos para a produção do escritor do que desenvolver aspectos antes trabalhados.

Um dos rompimentos se dá pela figuração do homem. Crisóstomo é um personagem que nutre um cuidado pelo mundo e pelo ânimo dos demais. Esse movimento se associa à ideia de sua identidade literária, que busca incorporar o elemento feminino até no nome (Mãe). Essa identidade criada pelo escritor também se conecta às mães e mulheres que povoam o universo narrativo. Como provedoras de vida, elas atuam em prol das crianças e contribuem para a organização, reprodução e transformação dos laços sociais. Ao mesmo tempo, a descoberta dessa qualidade, ligada ao universo feminino, faz de Crisóstomo o pai perfeito. Sentindo-se incompleto, seu sonho revela uma cosmovisão que parece uma resposta ao corpo social esfacelado. Cito (Capítulo dezessete - Sonho do homem aos quarenta anos):

O Crisóstomo pensava que o corpo dos homens estava condenado a uma tristeza maior, como se fosse o corpo fraco da humanidade, o corpo menor. O corpo triste. Pensava que a pele devia ser mais terra, e sonhava com fazer nascer árvores no peito e flores pelos braços e ter rios a correr por sob as pernas e entornar nas coxas giestas fartas e um milharal inteiro... Ele sonhava que sob o barco vogavam na água escura da noite milhões de filhos enroscados sobre si mesmos à espera do milagre do chamamento das mulheres. Sonhava que os peixes passavam pelos filhos e os adoravam como deuses, não entendendo que eram apenas gente. Pescar deuses, pensava. O Crisóstomo sonhava que deitava a rede e que ao subi-la poderia trazer um filho para dentro da sua barriga. Como se um deus ali aparecesse por eterna generosidade... Um a um, abria-lhes a caixa do perito e ajeitava lá dentro um coração. Tinha dito ao coração as palavras mais importantes de não esquecer. Ao fechar-lhes a caixa do perito, sossegados, os deuses adormeciam e sonhavam também com o Crisóstomo e assim estariam para sempre num sentimento recíproco, fundador. Todos os filhos aprendiam por natureza o amor (MÃE, 2011, p. 181-3).

A partilha do mistério da geração, representada na imagem onírica do pescador de deuses, permite a Crisóstomo ter um vislumbre da profundidade da criação humana. Transponho essa cena para outros níveis. A arte, nesse panorama, assim como a criação 
onírica ou outras produções da psique humana, constitui-se como uma espécie de provedora de vida. A narrativa de Valter Hugo Mãe caracteriza-se, nessa leitura, pela educação sentimental como uma resposta à mecanização dos tempos e seu efeito desumanizador. Os laços afetivos são fruto do longo aprendizado por que vemos passar os personagens do romance. O contato com o outro está no centro da maior parte do texto ficcional e os momentos de solidão individual (os personagens caem para dentro de si mesmos) condensam a educação para abertura ao outro, especialmente a partir da comunhão dos personagens com a natureza. Esse investimento em um tempo lento e esvaziado, na imagem da natureza grandiosa, nos artifícios da arte e no humano parecem se contrapor ao caráter da nossa sociedade, “destituída de mundo". Cito o filósofo esloveno Slavoj Zizek:

O caráter "destituído de mundo" do capitalismo está ligado a esse papel hegemônico do discurso científico na modernidade. Hegel já detectara claramente esse traço ao notar que, para nós (modernos), a arte e a religião já não impõem um respeito absoluto: podemos admirá-las, mas não nos ajoelhamos mais diante delas, nosso coração não está mais na realidade com elas. Só a ciência - o conhecimento conceitual - merece aquele respeito de outrora. ... Não é de se espantar que a modernidade conduza à chamada "crise do sentido", quer dizer, à desintegração da ligação, ou até da identidade, entre verdade e significação (ZIZEK, 2014, p.62)

Nesse sentido, poderia talvez argumentar sobre a irrupção do fantástico na narrativa como uma contribuição ao coro contrário a essa mecanização que destitui o mundo de encanto, paixão e humanidade. Os episódios que destoam da nossa realidade cotidiana geralmente marcam eventos em que a empatia é sublinhada na narrativa. Explicamos: a mãe de Isaura (mãe da mulher enjeitada, como é identificada em $O$ filho de mil homens), adquire um sotaque estranho e piora à medida que não aceita sua filha; a anã morre destroçada depois de dar à luz Camilo, em meio à vila em que ela é odiada por, pelo menos, quinze mulheres (casadas com os prováveis pais); Rosinha (caseira de uma moradora do campo) morre após cozinhar a galinha gigante do velho Gemúndio (viúvo idoso e entrevado), com quem casa por interesse e contrariando o amor que sente pelo velho do cerco. A falta de empatia ou o descompromisso ético para com o outro faz com que os personagens decaiam. Todos, inclusive, caem para dentro de si na narrativa desse romance. Essa queda parece fundamental ao crescimento de Camilo, Crisóstomo ou Isaura. Essas outras personagens que morrem de maneira mágica, caem num abismo insondável (como aquele que acompanha a incomunicável mãe de Isaura até a morte), pois romperam os laços de humanidade que as retinha no mesmo plano que os vivos. O episódio de Rosinha, 
cuja última interação com a filha é violenta (tenta chutá-la, chamando-a "estafermo de rapariga"), condensa aspectos que contribuem para a leitura: rompendo deliberadamente com os laços amorosos, sociais e humanos que a prendem ao mundo da experiência efetiva (e afetiva), ela inverte casamento por funeral. A garantia de laços com a comunidade, com o outro é imprescindível - e a subtração mágica dos personagens que desobedecem a essa ordem é lida como sinal do projeto de educação sentimental que tento delinear. A ruptura com o outro fica marcada pelo sinal da morte. Vale salientar também que o fantástico surge muitas vezes atrelado à natureza: Crisóstomo senta na areia da praia e pede pelo filho e mulher; a galinha gigante aparece num dia de tempestade.

Gostaria de analisar outra imagem do romance para continuar o comentário dos aspectos que elegi como característicos da "resposta à decadência" que o escritor desenvolve em relação à sociedade em que vive. Chamo resposta por considerar, além dos romances em questão, a performance pública do autor. A imagem diz respeito ainda a esse entrelaçamento entre fantástico (investimento explícito na arte), empatia (investimento no humano) e um tempo menos mecanizado. Cito:

Estava um anão sentado ao pé da escola. Não fazia mais do que ser pequeno e estar sentado. Diziam dele, as crianças, as histórias mais estapafúrdias. Que era duende e fazia magias, que vinha por mal e matava quem lhe falasse, que era do circo, vomitava cobras, tinha dentes de ferro, falava chinês, voava dos canhões, não tinha sexo, comia do lixo, tinha seis dedos em cada pé, lia os pensamentos, vivia nas raízes das árvores, tinha peixes a nadar vivos na barriga gorda, nasciam-lhe filhos nas barrigas das pernas, viajava numa nuvem, chorava rios, via tudo e sabia tudo. O Camilo, que nunca até então vira um anão, não percebeu sequer tanta coisa que os outros miúdos comentavam. Passou diante do banco e disse: boa tarde. O anão, educado, respondeu: boa tarde. E o Camilo não pensou mais nisso (MÃE, 2011, 201).

A introdução desse personagem sem nome próprio ("um anão") ao final da narrativa é um interessante ponto para a leitura. Esse trecho é colocado no último capítulo, no percurso que Camilo faz antes de chegar a seu destino: o funeral do velho Gemúndio, lugar em que encontrará e abraçará Antonino, confirmando a união familiar. No trajeto, passa pela escola - lugar obviamente associado à educação - onde está sentado o anão. Homem pequeno, o anão serve como uma alusão simbólica à desimportância - "não fazia mais do que ser pequeno e estar sentado". O narrador distende-se para falar sobre os boatos que rondam a figura desse homem diferente, histórias consideradas “estapafúrdias". Nesse sentido, pensamos que o narrador mantém uma linha ética frente a seus personagens (a morte mágica também reforça essa ideia). Mesmo rechaçando os absurdos propalados nas histórias daquelas crianças, o narrador os elenca. Camilo, que passa pelo anão, 
apressado e "ansioso" para falar com Antonino, tem sua experiência descrita pelo narrador. Até então nunca vira um anão e não pensou mais nisso. Diferente das outras crianças, Camilo aproxima-se mais da maturidade. Embora não saiba, ele tem muito em comum com o anão. Mesmo não o sabendo, ele aprendeu o valor da empatia como forma de melhorar o mundo. A cena final registra o encontro da criança com Antonino - um momento de reconciliação entre os personagens - e a união no abraço com o pai - tudo isso durante o funeral.

Há uma tentativa de galvanizar as experiências. O tempo tem uma dimensão fluida e lenta: o fluxo narrativo se distende sobre as cenas, os termos são repetidos ou parafraseados (dando movimento ao texto), diferentes pontos de vistas são ressaltados, a transformação dos personagens ocorre paulatinamente. A natureza está em simpatia com o homem: os personagens se integram a ela, a casa é um prolongamento da praia, eles vivem do que criam e cultivam. O homem está no centro da reflexão do romance: é através dos laços criados com outros que temos segurança, só assim o homem pode viver sem cair no abismo da solidão irremediável. A própria ideia de homem adquire uma relação imediata com a coletividade (daí a celebração da família expandida, a ideia do filho de mil homens). A arte é movimento simbólico articulado por Valter Hugo Mãe em vários níveis: o escritor "acha e quer muito" "que a arte (assim como o homem) salve o mundo, aliás, o mundo se apresenta para ele como desafio e cada um de nós como uma tentativa de superação/solução ${ }^{7}$. Assim, a arte é sua contribuição e apresenta um componente utópico e esperançoso. Além disso, há uma grande preocupação com o acabamento estético de suas obras - o fantástico, assim como traços estilísticos líricos ${ }^{8}$, comparecem aos romances por conta do seu investimento na mobilização estético-simbólica associada às artes.

O filho de mil homens assume, nessa leitura, a posição de uma resposta à decadência familiar. O romance de Valter Hugo Mãe coloca como ponto central a figura do "filho", mas aqui ele não aparece mais como desviante (tal qual Mundo em Cinzas do Norte, Hanno em Os Buddenbrooks, André em Lavoura Arcaica). Nos romances de decadência familiar, havia uma trajetória de deformação: confrontados com um mundo que os pressiona ou não comporta seus desejos, os personagens filhos decaíam. Camilo, por outro lado, passa por um aprendizado que culmina na sua formação como "um homem com a coragem toda para gostar de alguém". Além disso, a noção de "filho de mil homens" está extremamente conectada a ideia de uma coletivização do corpo social, de um cuidado solidário e

\footnotetext{
6 Texto extraído do libreto Fronteiras do Pensamento, temporada de 2015, "Como viver juntos".

${ }^{7}$ Entrevista dada à Revista da Cultura, 29.07.2015, "Os fiordes de todos nós”.

8 Antes de mais, Valter Hugo Mãe é poeta, e seu início como romancista é “tardio”.
} 
partilhado para com as novas gerações. A influência coletivista, que, diante daquela representação da família tradicional, ameaçava desagregar o sistema patriarcal é absorvida nesse romance. Daí também a ruptura com o próprio conceito de família (e consequentemente a desestabilização dos limites estabelecidos entre público e privado), conceito que se expande para além dos laços sanguíneos e das relações pré-estabelecidas a família é forma de encontro e de pertença.

A narrativa de Valter Hugo Mãe apresenta, assim, uma espécie de ruptura com a tradição da representação da família em desordem, pois o desejo de ordem é substituído pela primazia do afeto.

"As emoções dão tamanhos. Porque, se intensificadas, passam as pessoas nos caminhos mais estreitos como se alassem de plumas e perfumes e pasmassem com elas até as pedras do chão" (MÃE, 2011, p. 173). O bom cultivo das emoções é crucial na articulação do romance e caracteriza a centralidade da imagem da família na narrativa. Ao se opor às narrativas de maldição familiar, Valter Hugo articula família e felicidade, convívio e afeto, explorando as possibilidades da lei do amor. Despojando-se da necessidade de repetição da tragédia familiar que transpassa as representações literárias, assim como rechaçando o limite e a morte que envolvem a particularidade irredutível afirmada por Antígona, o escritor português cria um universo em que a afetividade pode ser reencenada e tomar lugar de importância simbólica na construção dos laços sociais. Diz-nos Paulo Angelini em sua recensão do romance: “ Talvez haja, de fato, a necessidade de silenciarmos o nosso discurso cínico e pessimista, ratificando um processo de reeducação simbólica às novas gerações. Talvez precisemos rever a valorização do individualismo, recuperar a crença na possibilidade de uma felicidade que nasce através do afeto" (ANGELINI, 2012, p. 247).

\section{REFERÊNCIAS}

ANGELINI, Paulo Ricardo Kralik. Recensão de O filho de mil homens. Navegações. Rio

Grande do Sul/Lisboa, vol. 5, n2, 2012.

BUTLER, Judith. El grito de Antígona. Tradutora (para o espanhol): Esther Oliver.

Barcelona: El Roure, 2001.

DELEUZE, Gilles; GUATTARI, Félix. O anti-Édipo: capitalismo e esquizofrenia 1. Trad. de

Luiz B. Orlandi. São Paulo: Ed. 34, 2010.

MÃE, Valter Hugo. O remorso de Baltaz̧ar Serapião. São Paulo: 34, 2014.

Nosso reino. São Paulo: 34, 2012.

. O apocalipse dos trabalhadores. São Paulo: Cosac Naify, 2013.

. A máquina de fazerer espanbóis. São Paulo: Cosac Naify, 2011. 
O filho de mil homens. São Paulo: Cosac Naify, 2011.

QUARESMA, Paulo Sergio Andrade. A morte, os mortos e o morrer na Crônica da casa assassinada de Lúcio Cardoso. 2007. 251 f. Dissertação (Mestrado em História da Literatura) Fundação Universidade Federal do Rio Grande, Rio Grande do Sul, 2007.

ROUDINESCO, Elisabeth. A Família em desordem. Rio de Janeiro: Jorge Zahar Ed, 2003.

ZIZEK, Slavoj. Violência: seis reflexões laterais. Trad. Miguel Serras Pereira. São Paulo:

Boitempo, 2014. 